\title{
1 Ecological consequences of urbanization on a legume-rhizobia mutualism
}

3 David Murray-Stoker ${ }^{1,2,3, *}$ and Marc T. J. Johnson ${ }^{2,3}$

4

$5{ }^{1}$ Department of Ecology and Evolutionary Biology, University of Toronto, Toronto, Ontario

6 M5S 3B2, Canada

$7 \quad{ }^{2}$ Department of Biology, University of Toronto Mississauga, Mississauga, Ontario, Canada L5L

$8 \quad 1 \mathrm{C} 6$

$9{ }^{3}$ Centre for Urban Environments, University of Toronto Mississauga, Mississauga, Ontario,

10 Canada L5L 1 C6

11 *Corresponding author: David Murray-Stoker dstoker92@ gmail.com

12

13 David Murray-Stoker, ORCID https://orcid.org/0000-0002-4774-6948

14 Marc T. J. Johnson, ORCID http://orcid.org/0000-0001-9719-0522 


\section{Abstract}

16 Mutualisms are key determinants of community assembly and composition, but urbanization can

17 alter the dynamics of these interactions and associated effects on ecosystem functions. Legume-

18 rhizobia mutualisms are a model interaction to evaluate the ecological and ecosystem-level

19 effects of urbanization, particularly urban-driven eutrophication and nitrogen (N) deposition.

20 Here, we evaluated how urbanization affected the ecology of the mutualism between white

21 clover (Trifolium repens) and its rhizobial symbiont (Rhizobium leguminosarum symbiovar

22 trifolii) along an urbanization gradient. We found that the abundance of rhizobium nodules on

23 white clover decreased with urbanization. White clover acquired $\mathrm{N}$ from mixed sources of $\mathrm{N}$

24 fixation and uptake from the soil for the majority of the urbanization gradient, but white clover

25 primarily acquired $\mathrm{N}$ from the soil rather than $\mathrm{N}$ fixation by rhizobia at the urban and rural limits

26 of the gradient. Importantly, we identified soil $\mathrm{N}$ as a critical nexus for urban-driven changes in

27 the white clover-rhizobium mutualism. Taken together, our results demonstrate that urbanization

28 alters the ecological consequences of a legume-rhizobium mutualism, with direct and indirect

29 effects of the urban landscape on an ecologically-important mutualistic interaction.

30 Keywords: mutualism, nitrogen, stable isotopes, urban ecology 


\section{Introduction}

32 Urbanization is a major driver of ecosystem change at local and global scales, consistently

33 altering the ecological setting in terms of both biotic and abiotic factors (Grimm et al. 2008, Seto

34 et al. 2010). Biotic changes frequently include fragmented habitats, homogenization of species

35 composition, reduced abundance and diversity of native species, reduced vegetation cover, and

36 increased abundance of non-native species (McKinney 2002, Grimm et al. 2008, Groffman et al.

37 2014, Aronson et al. 2016). Common changes to the abiotic environment include increased

38 impervious surface cover, elevated temperatures, higher pollution levels (e.g., air, water, light,

39 noise), and increased nutrient deposition (Grimm et al. 2008, Groffman et al. 2014, Stevens et al.

40 2018). However, there is limited research regarding the direct and indirect impacts of biotic and

41 abiotic changes on species interactions in urban environments (Youngsteadt et al. 2015, Miles et

42 al. 2019). Elucidating how urbanization affects the ecological consequences of species

43 interactions is important for understanding the drivers of biodiversity and ecosystem change in

44 urban environments.

45 Species interactions are key determinants of community composition (Wisz et al. 2013,

46 Leibold and Chase 2017), but urbanization can disrupt these interactions (Raupp et al. 2010,

47 Aronson et al. 2016, Miles et al. 2019) and their associated ecosystem functions (Ziter 2016). In

48 urban landscapes, natural habitats are frequently fragmented and degraded, which can result in

49 reduced species diversity and altered community composition (Williams et al. 2009, Aronson et

50 al. 2016). Such ecological changes can alter antagonistic interactions (e.g., predator-prey, host-

51 parasite; Rocha and Fellowes 2018, Parsons et al. 2019), competition (De León et al. 2019,

52 Thomson and Page 2020), and mutualisms (Irwin et al. 2014, Rocha and Fellowes 2018, Rivkin

53 et al. 2020). Mutualisms can be important for community and ecosystem stability, and 
54 disruptions to these interactions caused by urbanization may be particularly problematic for

55 maintaining ecosystem functions. For example, pollinator abundance, diversity, and composition

56 often change with urbanization (Harrison et al. 2018, Santangelo et al. 2020), which can shift the

57 balance of the benefits conveyed between interacting plants and pollinators (Irwin et al. 2014,

58 Rivkin et al. 2020, Santangelo et al. 2020). As another example, plant-microbe interactions are

59 important for community assembly and nutrient cycling (van der Heijden et al. 2008), and

60 urbanization can affect these interactions through altered soil chemistry mediated by pollution

61 and nutrient deposition (Grimm et al. 2008, Stevens et al. 2018). As plant-microbe interactions

62 are frequently nutrient-provisioning mutualisms, pollution and nutrient deposition that cause

63 changes in the diversity and composition of microbial communities can have cascading effects

64 on nutrient cycles in urban ecosystems (Galloway et al. 2003, Kaye et al. 2006). More broadly, if

65 urbanization frequently alters mutualistic interactions, this may have cascading effects on

66 communities and ecosystems.

67 Mutualisms between legumes and rhizobia are an ideal system for evaluating the ecological

68 impacts of urbanization on species interactions. In these mutualisms, rhizobia fix atmospheric

69 nitrogen in exchange for photosynthate and housing in nodules by their host plant (Hirsch 1992,

70 Poole et al. 2018). Urbanization can disrupt these interactions, specifically through nitrogen (N)

71 deposition and enrichment (Grimm et al. 2008, Zhang et al. 2012). Nitrogen deposition can

72 inhibit the formation of nodules (Streeter and Wong 1988, Omrane and Chiurazzi 2009),

73 precluding the development of the mutualism or reducing plant reliance on rhizobia for

74 providing N (Vergeer et al. 2008, Weese et al. 2015, Regus et al. 2017). Additionally, N

75 deposition can reduce $\mathrm{N}$ fixation rates by rhizobia (Cleland and Harpole 2010, Zheng et al.

76 2019). Although $\mathrm{N}$ deposition and short-term application of nutrient-rich fertilizers can benefit 
77 both legumes and rhizobia (Simonsen et al. 2015, Forrester and Ashman 2018), chronic and

78 long-term exposure to increased $\mathrm{N}$ can reduce the ecological benefits of $\mathrm{N}$ fixation and cause the

79 evolution of less beneficial rhizobia (Weese et al. 2015, Regus et al. 2017). Using the legume-

80 rhizobia mutualism as a model system, it is possible to study how urbanization and nutrient

81 deposition alter interactions in an ecologically-important mutualism.

82 In this study, we evaluated the hypothesis that urbanization alters the ecological and

83 ecosystem-level consequences of a nutrient-provisioning mutualism. We used the mutualism

84 between the legume white clover (Trifolium repens) and its rhizobial symbiont (Rhizobium

85 leguminosarum symbiovar trifolii) as a tractable model interaction. We conducted our study

86 along an urbanization gradient in Toronto, Canada (Fig. 1). Our study focused on three primary

87 questions: (Q1) does rhizobia nodulation vary along an urbanization gradient? (Q2) How does

88 the source of plant nitrogen (i.e., from soil or gaseous $\mathrm{N}_{2}$ fixed by rhizobia) change along the

89 urbanization gradient? And (Q3) how do urban landscape features influence the interactions

90 between soil $\mathrm{N}$, plant $\mathrm{N}$, and rhizobia nodulation? We predicted that: (1) urbanization would alter

91 investment in rhizobia by $T$. repens, causing increased nodulation with decreased urbanization;

92 (2) increased $\mathrm{N}$ availability in the soil due to urbanization would reduce $\mathrm{N}$ fixation by rhizobia

93 and alter the source of $\mathrm{N}$ for T. repens; and (3) the changes in landscape features associated with

94 urbanization cause direct and indirect effects on ecosystem structure and the white clover-

95 rhizobium mutualism (Fig. 2).

96 Materials and Methods

97 Land acknowledgement

98 We conducted our sampling at 49 sites along an urbanization gradient in the Greater Toronto

99 Area of Ontario, Canada in August 2018 (Fig. 1). Our sampling was conducted on the traditional 
100 land of the Huron-Wendat, the Seneca, and most recently, the Mississaugas of the Credit First

$101 \quad$ Nation.

102 Study organisms

103 White clover (Trifolium repens L., Fabaceae) is a perennial, herbaceous legume native to Eurasia

104 that is now globally distributed (Baker and Williams 1987). White clover typically reproduces

105 clonally through stolons (Kemball and Marshall 1995) as well as through seed via obligately-

106 outcrossed flowers (Barrett and Silander 1992). Rhizobium leguminosarum symbiovar trifolii is

107 the primary rhizobial symbiont of T. repens (Martínez-Romero and Caballero-Mellado 1996,

108 Andrews and Andrews 2017). As a facultative symbiont, $R$. l. bv. trifolii fixes atmospheric $\mathrm{N}_{2}$

109 into accessible $\mathrm{NH}_{3}$ for white clover in exchange for photosynthate and hosting within root

110 nodules.

111 Nodulation is initiated when rhizobia attach to and penetrate the root. After infection of

112 the root they continue to divide within the plant host cells to form nodules (Poole et al. 2018). At

113 this stage, rhizobia differentiate into bacteroids and begin the $\mathrm{N}$ fixation process, whereby

114 atmospheric $\mathrm{N}_{2}$ is converted into $\mathrm{NH}_{3}$ by bacteroids with the aid of nitrogenase enzymes (Hirsch

115 1992, Poole et al. 2018). Urbanization and specifically $\mathrm{N}$ enrichment may inhibit nodulation at

116 multiple steps of the process. For example, $\mathrm{NO}_{3}$ and $\mathrm{NH}_{3}$ can inhibit rhizobia infection of roots,

117 the formation of nodules, or the activity of nitrogenase (Streeter and Wong 1988, Omrane and

118 Chiurazzi 2009). Another common mechanism for reduced nodulation with increased N

119 availability is plant hosts switching $\mathrm{N}$ sources from $\mathrm{N}$ fixed by rhizobia to $\mathrm{N}$ taken up directly

120 from the soil, resulting in lower nodulation and less investment in the symbiosis (Heath et al.

121 2010, Regus et al. 2017).

$122 \quad$ Field sampling 
123 Field collections of white clover, associated rhizobia, and soil samples were collected at all 49

124 sites along the urbanization gradient (Fig. 1). At each site, 9-10 clover individuals and associated

125 roots and nodules were collected (mean $\pm \mathrm{SE}=9.94+0.13$ individuals). Twenty soil cores were

126 also taken at each sampling location, with 10 cores taken immediately adjacent to collected white

127 clover and 10 taken at least $5 \mathrm{~m}$ from the nearest white clover plant (hereafter "bulk" cores), with

128 the requirement that bulk cores did not contain other nitrogen-fixing legumes (e.g., Medicago

129 lupulina). Each soil core was taken to a depth of $5 \mathrm{~cm}$, and the top $2 \mathrm{~cm}$ plus organic material

130 were removed because they could confound estimates of soil nutrients. Each sample type (bulk

131 and adjacent) was combined for a composite sample of each soil core type per site, which were

132 stored at $-80^{\circ} \mathrm{C}$ until subsequent processing.

\section{Lab processing}

134 Plant processing and nodule quantification: White clover samples were separated into leaf and

135 root tissue. Leaf tissue was collected for stable isotope analyses by cutting 6-10 fully expanded,

136 green, non-senescing leaves from each individual, which were placed into a $2 \mathrm{~mL}$ tube and

137 stored in a freezer at $-20^{\circ} \mathrm{C}$ until later processing. Root tissue was collected by cutting the first

138 five roots below the plant base and directly attached to the stolon. Roots were measured to the

139 nearest $1 \mathrm{~mm}$ until at least $10 \mathrm{~cm}$ of root length were measured or all collected roots were

140 measured (root length: mean $\pm \mathrm{SE}=10.3 \pm 0.13$, range $=1.8-17.7 \mathrm{~cm}$ ). Nodules were counted

141 visually for each measured root, and counts were standardized by the total length of root

142 measured to generate an estimate of nodule density per $\mathrm{cm}$ of root per plant.

143 Soil sample processing: Soil samples were prepared for $\mathrm{N}$ analyses by filtering, grinding,

144 homogenizing, and drying samples. Samples were taken out of storage in the freezer at $-80^{\circ} \mathrm{C}$

145 and thawed overnight in the lab $\left(21.5^{\circ} \mathrm{C}\right)$. Each sample was then filtered over stacked sieves 
146 (mesh diameters: $4.75 \mathrm{~mm}, 2 \mathrm{~mm}, 1 \mathrm{~mm}$, and $0.5 \mathrm{~mm}$ ) to remove large rocks and gravel. Soil

147 retained on the $0.5 \mathrm{~mm}$ sieve and catch pan was collected, and then samples were dried and

148 stored at $60^{\circ} \mathrm{C}$ for $48 \mathrm{hrs}$. Samples were homogenized into a fine powder using mortar and pestle

149 and stored in a drying oven at $60^{\circ} \mathrm{C}$ for approximately 4 weeks until later processing. Adjacent

150 soil $\mathrm{N}$ provided an estimate of $\mathrm{N}$ available to white clover individuals and potentially affected by

$151 \quad \mathrm{~N}$-fixing rhizobia, and bulk soil $\mathrm{N}$ was a measure of background $\mathrm{N}$ availability at the site;

152 adjacent and bulk soil were measured separately.

153 Leaf processing: Leaf samples were prepared for $\mathrm{N}$ analyses by freeze-drying, grinding, and

154 drying the tissue. A composite sample for each population was prepared by taking one leaf from

155 each of the white clover individuals per site and the composite samples were freeze-dried and

156 then homogenized using a tissue grinder (FastPrep 96, MP Biomedicals, Irvine, CA, USA).

157 Samples were dried and stored in a drying oven to achieve a constant mass at $60^{\circ} \mathrm{C}$ for $24-48 \mathrm{hrs}$

158 until later processing.

159 Soil and plant $N$ analyses: Soil and plant samples were weighed (soil $\approx 30 \mathrm{mg}$, plant $\approx 2 \mathrm{mg}$ ) on

160 a micro-balance (XP2U Mettler Toledo, Mississauga, ON, Canada) and packed into aluminum

161 capsules (Costech Analytical Technologies Inc., Valencia, CA, USA). Soil samples were

162 analyzed for \% N using a Carlo Erba NA 1500C/H/N Analyzer (Carlo Erba Strumentazione,

163 Milan, Italy). Plant tissue was simultaneously analyzed for $\% \mathrm{~N}$ and $\mathrm{N}$ isotopes (i.e., ${ }^{15 / 14} \mathrm{~N}$ )

164 using a Carlo Erba NA 1500C/H/N Analyzer coupled to a Thermo Delta V IRMS system

165 (Thermo Fisher Scientific, Waltham, MA, USA). Nitrogen stable isotopes were expressed

166 relative to a standard in $\delta$ notation:

167

$$
\delta=\left[\left(R_{\text {sample }}-R_{\text {standard }}\right)-1\right] \times 1000 \% \text { o }
$$


168 where R represents the ratio of ${ }^{15} \mathrm{~N}$ to ${ }^{14} \mathrm{~N}$. Plants depleted in $\delta^{15} \mathrm{~N}$ (i.e., lower $\delta^{15} \mathrm{~N}$ ) suggests $\mathrm{N}$

169 acquisition primarily from $\mathrm{N}$ fixation, while plants enriched in $\delta^{15} \mathrm{~N}$ (i.e., higher $\delta^{15} \mathrm{~N}$ ) suggests $\mathrm{N}$

170 acquisition primarily from the soil (Högberg 1997, Craine et al. 2015). All elemental and stable

171 isotope analyses were conducted at the Stable Isotope Ecology Laboratory at the University of

172 Georgia, USA (http://siel.uga.edu/).

173 Landscape metrics

174 Land use and land cover metrics were calculated for each site to quantify urbanization. We

175 calculated percent impervious surface cover (ISC) manually using Google Earth Pro 7.3.2.5776

176 (Google Inc., Mountain View, CA, USA) by drawing a 100-m radius around each site and using

177 the polygon tool to draw and measure ISC. We also calculated the normalized difference

178 vegetation index (NDVI), a measure of vegetation cover or site 'greenness', for each site from

179 landsat imagery using the "MODISTools" package in R (version 1.1.1; Tuck et al. 2014). We

180 calculated NDVI from 1 June to 31 August at 16-day intervals for each year from 2014-2018 to

181 generate a mean NDVI for each site; NDVI was measured at a spatial resolution of $250 \mathrm{~m}$. Each

182 site received 6 measurements per year for a total of 30 measurements, and we calculated the

183 mean NDVI for each site from these 30 measurements. Finally, for each site, we calculated the

184 distance from the urban center as the distance on an ellipsoid (i.e., geodesic distance) using the

185 "geosphere" package (version 1.5-10; Hijmans 2019); coordinates for the urban center were

186 selected as Toronto City Hall $\left(43.651536^{\circ} \mathrm{N},-79.383276^{\circ} \mathrm{W}\right)$. Distance from the urban center has

187 been shown to be correlated with multiple measures of urbanization in Toronto, and it has been

188 identified as an important predictor of the ecological and evolutionary effects of urbanization for

189 T. repens and other systems (Thompson et al. 2016, Johnson et al. 2018, Rivkin et al. 2020).

190 Statistical analyses 
191 Nodule density mixed-effects models: We used linear mixed-effects models to analyze the

192 response of nodule density against distance from the urban center, percent ISC, and NDVI. We

193 fitted the linear mixed-effects models as:

$$
\text { nodule density }=\text { intercept }+x_{i}+(1 \mid \text { site })+e_{i}
$$

195 where nodule density was the response, $x_{i}$ was the fixed effect (distance from the urban center,

196 percent ISC, or NDVI), site was a random effect, and $e_{i}$ was the residual error associated with the

197 fixed effect. A full model with all predictor variables was not fitted because high

198 multicollinearity between variables (Pearson $r>|0.5|$ ) made it difficult to disentangle the effects

199 of individual variables (Supplementary material Appendix 1 Fig. A1). Instead, we used structural

200 equation modelling (see below) to integrate the variables into a single analysis.

201 All linear mixed-effects models were fitted using the "lme4" (version 1.1-25, Bates et al.

202 2015) and "ImerTest" (version 3.1-2; Kuznetsova et al. 2017) packages, with models estimated

203 using restricted maximum likelihood. We calculated partial $F$-tests of fixed effects using Type II

204 sums-of-squares, and denominator degrees of freedom were approximated using the

205 Satterthwaite correction for finite sample sizes (Satterthwaite 1946). Response and predictor

206 variables were standardized to a mean of 0 and standard deviation of 1 prior to analyses, and

207 model assumptions were inspected using the DHARMa package (version 0.3.3.0; Hartig 2020).

208 Conditional $\mathrm{R}^{2}$, a measure of the variance explained by the fixed and random effects (Nakagawa

209 et al. 2017), was calculated for the models using the "r.squaredGLMM()" function in the

210 “MuMIn” package (version 1.43.17; Barton 2020).

211 White clover $\delta^{15} N$ and soil $N$ generalized additive models: Changes in white clover $\delta^{15} \mathrm{~N}$ and soil

$212 \mathrm{~N}$ (bulk and adjacent) in response to urbanization were analyzed using generalized additive

213 models (GAMs) using the "mgcv" package (version 1.8-33; Wood 2011, 2017). Generalized 
214 additive models are a flexible approach for analyzing data, as non-linear predictors can be fitted

215 with non-parametric smoothing functions to identify effects of the predictors (Hastie and

216 Tibshirani 1986, Wood 2017). We fitted the GAMs as:

$$
y_{i}=\text { intercept }+s\left(x_{i}\right)+e_{i}
$$

218 where $y_{i}$ was the response (white clover $\delta^{15} \mathrm{~N}$, bulk soil $\mathrm{N}$, or adjacent soil $\mathrm{N}$ ), $x_{i}$ was the

219 predictor (distance from the urban center, percent ISC, or NDVI), $s$ was the non-linear

220 smoothing function for the associated predictor, and $e_{i}$ was the residual error. Thin-plate

221 regression splines with shrinkage terms (method call: bs = "ts") were used to smooth all

222 predictors (Wood 2003), and each smooth estimate was constrained to a mean of zero. Residual

223 error was assumed independent with a mean of zero and constant variance. White clover $\delta^{15} \mathrm{~N}$

224 GAMs were fitted to a Gaussian distribution and soil N GAMs were fitted with a logit link to the

225 "betar" distribution, part of the "mgcv" family, to model non-binomial, proportional data.

226 Similar to the nodule density mixed-effects models, high concurvity between variables (Pearson

$227 \mathrm{r}>|0.5|$ ) precluded the use of a single GAM with all predictor variables (Supplementary material

228 Appendix 1 Fig. A1). Instead, all variables were integrated into the structural equation model

229 (detailed below). All GAMs were estimated using maximum likelihood.

230 Path analysis: A structural equation model (SEM) was constructed to evaluate the direct and

231 indirect causal pathways through which distance from the urban center, percent ISC, NDVI, soil

$232 \mathrm{~N}$ (bulk and adjacent), nodule density, and white clover $\delta^{15} \mathrm{~N}$ interact. Basic univariate and

233 multivariate equations are considered structural if there is sufficient evidence that the predictor

234 or set of predictors has a causal effect on the response (Grace 2006), and SEM is the modelling

235 of a multivariate relationship with two or more structural equations. The robustness of a SEM is

236 based on the overall model fit to the data rather than individual causal pathways within the model 
237 (Mitchell 1992, Grace 2006, Grace et al. 2010). Model fit is assessed by comparing expected and

238 observed covariance between predictor and response variables in the SEM using $\chi^{2}$ tests

239 (Mitchell 1992, Grace 2006, Grace et al. 2010), and the SEM is considered consistent with the

240 data when expected and observed covariance of the SEM are not different. We fit the

241 hypothesized SEM (Fig. 2), including all causal and correlational pathways, and no removal or

242 addition of causal pathways occurred. Distance from the urban center was fitted as an exogenous

243 variable (i.e., independent variable that affects other variables but is not affected by other

244 variables), while all remaining variables were fitted as endogenous variables (i.e., variables

245 affected by the exogenous variable and that can affect other endogenous variables). Distance

246 from the urban center was fitted to account for extraneous sources of urbanization and

247 environmental variation not explained by the other predictors. All data were standardized by

248 scaling individual variables to a mean of 0 and standard deviation of 1 prior to analysis, and the

249 SEM was estimated using maximum likelihood with robust Satorra-Bentler scaled test statistics

250 (Satorra and Bentler 2001, Rosseel 2012).

251 Results of the SEM were reported as standardized path coefficients, which show the

252 direction and magnitude of causal pathways between variables and allow for comparison of the

253 strength of relationships within the SEM (Wright 1934, Mitchell 1992, Grace 2006). Direct

254 effects within the SEM are the standardized path coefficient associated with the causal pathway,

255 while indirect effects are quantified by multiplying each path coefficient linking one variable to

256 another within the SEM. For example, in the hypothesized SEM (Fig. 2), an indirect effect of

257 distance from the urban center on bulk soil $\mathrm{N}$ is quantified as the path coefficient of distance on

258 percent ISC (percent ISC distance) times the path coefficient of percent ISC on bulk soil $\mathrm{N}$

259 (bulk soil $\mathrm{N} \sim$ percent ISC). The sign (+ or - ) of an indirect effect is the sign of the last causal 
pathway in the link. Indirect or compounding pathways cannot be calculated across correlational pathways as the direction of the effect is not unidirectional (Wright 1934, Grace 2006). 2012). All above analyses were conducted using R (version 4.0.2; R Core Team 2020) in the

264 RStudio environment (version 1.4.869; RStudio Team 2020), with data management and figure

265 creation facilitated using the "tidyverse" (version 1.3.0; Wickham et al. 2019).

\section{Results}

267 Nodule density, white clover $\delta^{15} N$, and soil $N$

268 Urbanization had effects on nodule density, white clover $\delta^{15} \mathrm{~N}$, and soil $\mathrm{N}$, although the measure

269 and effect of urbanization varied among response variables. Nodule density increased with

270 increasing distance from the urban center $\left(\beta=0.146, \mathrm{SE}=0.066, \mathrm{P}=0.031, \mathrm{R}^{2}=0.147\right.$, Table 1 ,

271 Fig. 3) and NDVI $\left(\beta=0.152, \mathrm{SE}=0.064, \mathrm{P}=0.021, \mathrm{R}^{2}=0.146\right.$, Table 1, Fig. 3), and nodule

272 density decreased with increasing percent ISC $\left(\beta=-0.199, \mathrm{SE}=0.063, \mathrm{P}=0.003, \mathrm{R}^{2}=0.151\right.$,

273 Table 1, Fig. 3). These effects translated to an increase of (estimate \pm SE) $0.006 \pm 0.003$ in

274 nodules per $\mathrm{cm}$ of root (i.e., nodule density) for each $1 \mathrm{~km}$ from the city centre, $-0.004 \pm 0.001$

275 lower nodule density for each 1 percent increase in impervious surface cover, and $0.007 \pm 0.003$

276 greater nodule density for each 100 unit increase in NDVI (Supplementary material Appendix 1

277 Table A1). White clover $\delta^{15} \mathrm{~N}$ was strongly and non-linearly predicted by distance from the urban 278 center $\left(F=10.893, \mathrm{P}<0.001, \mathrm{R}^{2}=0.671\right.$, deviance explained $\left.=71.0 \%\right)$ but not percent ISC or

279 NDVI (Table 2, Fig. 4). White clover $\delta^{15} \mathrm{~N}$ was higher and positive at the urban $(0-10 \mathrm{~km})$ and 280 rural $(40-47 \mathrm{~km})$ extremes of the gradient, while white clover $\delta^{15} \mathrm{~N}$ was lower and negative for

281 the majority of the gradient $(10-40 \mathrm{~km}$, Fig. 4). Bulk soil $\mathrm{N}$ was predicted by distance from the

282 urban center $\left(\chi^{2}=3.097, \mathrm{P}=0.043, \mathrm{R}^{2}=0.079\right.$, deviance explained $=11 \%$; Supplementary 
material Appendix 1 Table A2, Fig. A2), where bulk soil N decreased with increasing distance

284 from the urban center. Additionally, bulk soil $\mathrm{N}$ was weakly predicted by percent ISC $\left(\chi^{2}=\right.$

286 Table A2, Fig. A2), where bulk soil $\mathrm{N}$ increased with increasing percent ISC; bulk soil $\mathrm{N}$ was not

287 predicted by NDVI (Supplementary material Appendix 1 Table A2, Fig. A2); adjacent soil N

288 (i.e., immediately surrounding the plant) was only weakly predicted by percent ISC $\left(\chi^{2}=2.277\right.$,

$289 \mathrm{P}=0.070, \mathrm{R}^{2}=0.069$, deviance explained $=9 \% ;$ Supplementary material Appendix 1 Table A2,

290 Fig. A2).

$291 \quad$ Path analysis

292 The SEM demonstrated that urbanization had direct and indirect effects on ecosystem structure

293 (i.e., soil N) and the white clover-rhizobium mutualism (Fig. 5). Our hypothesized SEM had

294 good fit between the predicted and observed covariance $\left(\chi^{2}=0.009, \mathrm{df}=1, \mathrm{P}=0.926\right.$, Fig. 5).

295 Distance from the urban center had a direct negative relationship with white clover $\delta^{15} \mathrm{~N}$ : as the

296 distance from the urban center increased, white clover $\delta^{15} \mathrm{~N}$ decreased (path coefficient $=-0.60$,

$297 \mathrm{SE}=0.16, \mathrm{P}<0.001)$. Bulk soil $\mathrm{N}$ decreased with increasing distance from the urban center

298 (path coefficient $=-0.29, \mathrm{SE}=0.18, \mathrm{P}=0.099$ ). Further effects of distance from the urban center

299 were mediated through percent ISC on nodule density $($ percent ISC $\sim$ distance path coefficient $=$

$300-0.55, \mathrm{SE}=0.11, \mathrm{P}<0.001 ;$ nodule density $\sim$ percent $\mathrm{ISC}$ path coefficient $=-0.39, \mathrm{SE}=0.23, \mathrm{P}$

$301=0.082$; compound path coefficient $=|-0.55| \mathrm{x}-0.39=-0.21)$. Although distance from the

302 urban center was positively related to NDVI (path coefficient $=0.63, \mathrm{SE}=0.08, \mathrm{P}<0.0001$ ),

303 there were no further effects of NDVI in the SEM. Percent ISC and NDVI were negatively

304 correlated (path coefficient $=-0.45, \mathrm{SE}=0.13, \mathrm{P}=0.001$ ). Bulk soil $\mathrm{N}$ had a negative effect on

305 white clover $\delta^{15} \mathrm{~N}$ (path coefficient $=-0.23, \mathrm{SE}=0.11, \mathrm{P}=0.040$ ), in which increased bulk soil 
$306 \mathrm{~N}$ decreased white clover $\delta^{15} \mathrm{~N}$. Nodule density and adjacent soil $\mathrm{N}$ were negatively correlated

307 (path coefficient $=-0.29, \mathrm{SE}=0.11, \mathrm{P}=0.010$ ). Bulk soil $\mathrm{N}$ was directly linked to distance from

308 the urban center and then embedded in correlational pathways between adjacent soil $\mathrm{N}$ and

309 nodule density (Fig. 5). All path coefficients and associated measures of variation are provided in

310 the supplement (Supplementary material Appendix 1 Table A3).

\section{Discussion}

312 Our results show that urbanization alters the ecology of the white clover-rhizobium mutualism

313 and associated patterns in soil nutrients, with support for this conclusion from three key results.

314 First, we observed increased investment in nodules by white clover with decreasing impervious

315 surface cover, increasing NDVI, and greater distance from the urban center (Q1). Second, we

316 found that the source of nitrogen used by white clover varied along the urbanization gradient

317 (Q2). White clover $\delta^{15} \mathrm{~N}$ suggested acquisition of $\mathrm{N}$ through $\mathrm{N}$-fixing rhizobia for the majority of

318 the urbanization gradient, although increased $\delta^{15} \mathrm{~N}$ at the urban and rural extremes suggested

319 direct uptake of $\mathrm{N}$ sources from the soil. Finally, we observed direct and indirect effects of

320 urbanization on ecosystem structure and white clover-rhizobium interactions (Q3). Urbanization

321 altered the landscape, changing the amount of green and impervious surface cover surrounding

322 each white clover population, with these changes cascading onto soil $\mathrm{N}$, nodule density, and

323 white clover $\delta^{15} \mathrm{~N}$. Given this evidence, our results suggest that urbanization alters the ecology of

324 the white clover-rhizobia mutualism through direct and indirect pathways.

325 Effects of urbanization on the white clover-rhizobium mutualism

326 Increasing urbanization is frequently associated with increased $\mathrm{N}$ deposition and enrichment

327 (Grimm et al. 2008, Zhang et al. 2012), and legumes are expected to have lower investment in

328 rhizobia with greater $\mathrm{N}$ availability in the soil (Heath and Tiffin 2007, Heath et al. 2010, Regus 
et al. 2017). Our results supported this prediction, whereby nodule density, a common measure

330 of investment in mutualistic interactions with rhizobia by host plants (Heath and Tiffin 2007 ,

331 Heath et al. 2010), increased with decreasing effects of urbanization; these results are supported

332 by other empirical studies in nonurban systems that found reduced investment in nodules with

333 increased N (Heath and Tiffin 2007, Heath et al. 2010, Lau et al. 2012). In our study, nodule

334 density was further influenced by the urban landscape and its effects on the local soil

335 environment. Increasing distance from the urban center was associated with negative effects on

336 bulk soil $\mathrm{N}$ and, while nodule density was also negatively related to impervious surface cover,

337 there were entangled dependencies between nodule density, bulk soil N, and adjacent soil N.

338 Given that soil N can regulate nodule formation and development (Streeter and Wong 1988,

339 Omrane and Chiurazzi 2009) and cause shifts in the cost-benefit balance of the white clover-

340 rhizobium mutualism (Lau et al. 2012, Weese et al. 2015, Regus et al. 2017), urban-driven

341 changes to local soil $\mathrm{N}$ is a likely driver linking urbanization to altered ecological dynamics in

342 the white clover-rhizobium mutualism.

343 In addition to nodule density, white clover $\delta^{15} \mathrm{~N}$ varied with urbanization. Comparing

344 relative $\delta^{15} \mathrm{~N}$ signatures allows for assessing and tracing the source of $\mathrm{N}$ used by plants (Högberg

345 1997, Robinson 2001, Craine et al. 2015). For the majority of the urbanization gradient, white

346 clover $\delta^{15} \mathrm{~N}$ was frequently bound between $-1 \%$ and $0 \%$, suggesting that white clover primarily

347 acquired $\mathrm{N}$ through fixation by rhizobia but other sources of $\mathrm{N}$ were also used (Högberg 1997 ,

348 Craine et al. 2015). By contrast, populations at the urban and rural extremes of the gradient

349 exhibited high values of $\delta^{15} \mathrm{~N}$, which suggests decreased reliance on rhizobia for $\mathrm{N}$ and increased

350 uptake of $\mathrm{N}$ from the soil. A potential explanation for this pattern is the application of fertilizer

351 and management practices. Fertilizer application can directly provide white clover with $\mathrm{N}$, 
352 reducing the need for white clover to invest in rhizobia (Vergeer et al. 2008, Heath et al. 2010)

353 and increasing plant $\delta^{15} \mathrm{~N}$ (Trammell et al. 2016, 2020). Nitrogen fertilizer use associated with

354 agricultural practices has increased over the past several decades in our study region (Clearwater

355 et al. 2016). Long-term $\mathrm{N}$ fertilization can lead to the evolution of less beneficial rhizobia

356 (Weese et al. 2015), which could explain the higher nodule density despite increased white

357 clover $\delta^{15} \mathrm{~N}$ (i.e., decreased $\mathrm{N}$ fixation) at the agriculturally-intensive rural end of the gradient.

358 This hypothesis will be investigated in future studies.

359 Although we did not use experimental plant lines to determine the $\delta^{15} \mathrm{~N}$ signatures of

360 white clover relying solely on N fixation or on soil acquisition (Högberg 1997, Robinson 2001,

361 Craine et al. 2015), white clover acquiring $\mathrm{N}$ solely through fixation by rhizobia has a $\delta^{15} \mathrm{~N}$ of -

$3622 \%$ o to $-1 \%$ o (Högberg 1997). Experimentally quantifying the contributions of $\mathrm{N}$ fixation and soil

363 uptake along the urbanization gradient would help elucidate the relative importance of these two

364 processes and pools of N. Our existing data show that urbanization is at least partially

365 responsible for variation in nodule density and white clover $\delta^{15} \mathrm{~N}$ due to shifts in the costs and

366 benefits of the rhizobia-plant host interaction.

367 White clover-rhizobium-soil interactions

368 Depleted $\delta^{15} \mathrm{~N}$ in legumes is associated with increased $\mathrm{N}$ fixation by rhizobia, and we expected

369 increased bulk soil $\mathrm{N}$ to lead to an increase in white clover $\delta^{15} \mathrm{~N}$ (i.e., decreased $\mathrm{N}$ fixation).

370 Contrary to our expectation, increased bulk soil $\mathrm{N}$ was associated with decreased white clover

$371 \delta^{15} \mathrm{~N}$ (i.e., increased $\mathrm{N}$ fixation). While contrary to our predictions, increased $\mathrm{N}$ can stimulate

372 nodulation, $\mathrm{N}$ fixation, and other metabolic processes in rhizobia (Streeter 1985, Simonsen et al.

3732015 , Forrester and Ashman 2018). We also predicted that lower white clover $\delta^{15} \mathrm{~N}$ would

374 increase adjacent soil $\mathrm{N}$ as a by-product of $\mathrm{N}$ fixation by rhizobia (Hirsch 1992, Poole et al. 
375 2018); this prediction was not supported. While both distance from the urban center and bulk soil

$376 \mathrm{~N}$ negatively affected white clover $\delta^{15} \mathrm{~N}$, we did not observe a direct link from white clover $\delta^{15} \mathrm{~N}$

377 to adjacent soil $\mathrm{N}$.

378 We predicted a positive link between nodule density and adjacent soil $\mathrm{N}$ as a

379 consequence of increased $\mathrm{N}$ fixation, which was expected to enrich soil with $\mathrm{N}$ when nodules

380 and plant tissue senesced (Hirsch 1992, Poole et al. 2018). We observed that nodule density was

381 negatively correlated to adjacent soil N. A potential explanation for this response is that white

382 clover produced fewer and larger nodules: larger nodules can convey greater benefits to white

383 clover, increasing N fixation and associated effects on soil N (Porter and Simms 2014, Gano-

384 Cohen et al. 2020). We only measured nodule count and density, so we were unable to test this

385 hypothesis. Our observation of increased adjacent soil $\mathrm{N}$ with decreasing nodule density is

386 consistent with inhibition of nodulation due to high N (Streeter and Wong 1988, Omrane and

387 Chiurazzi 2009). Conversely, decreased adjacent soil $\mathrm{N}$ with increased nodule densities could

388 also suggest less beneficial rhizobia that fix less $\mathrm{N}$ are colonizing roots, which could reduce the

389 enrichment of soil $\mathrm{N}$ resulting from the white clover-rhizobium mutualism. Manipulative

390 experiments are needed to disentangle these two possibilities to understand the causal

391 explanation for our observed patterns.

\section{Urbanization and soil nitrogen}

393 Urbanization had expected effects on soil N, but this was dependent on interactions between

394 white clover and rhizobium and their associated effects on soil and plant N. Bulk soil N was

395 greatest in urban areas, which was consistent with our predictions and observed patterns in other

396 studies (Pouyat et al. 2015, Regus et al. 2017, Trammell et al. 2020). Increased soil N is likely a

397 result of $\mathrm{N}$ deposition linked to urbanization (Grimm et al. 2008, Zhang et al. 2012, Regus et al. 
2017). Adjacent soil $\mathrm{N}$ showed a similar but weaker pattern to bulk soil $\mathrm{N}$ in response to

399 impervious surface cover. These results in combination with the SEM show that local soil $\mathrm{N}$ is

400 governed by exogenous $\mathrm{N}$ inputs (e.g., rain, synthetic fertilizer, pets) into the surrounding soils,

401 although the SEM also suggests a feedback between soil $\mathrm{N}$ and rhizobia as bulk and adjacent soil

$402 \mathrm{~N}$ were correlated, with adjacent soil $\mathrm{N}$ further dependent on nodule density. Taken together,

403 these lines of evidence suggest that the effects of urbanization on the white clover-rhizobium

404 mutualism are complex, with local variation in soil $\mathrm{N}$ influencing dynamics between white

405 clover, rhizobium, and soil and plant $\mathrm{N}$.

406 We quantified total soil $\mathrm{N}$ to answer our focal questions for this study, but other measures

407 of soil $\mathrm{N}$ can be important to consider. For example, total $\mathrm{N}$ does not discriminate between

408 different types of $\mathrm{N}$ (e.g., $\mathrm{NO}_{3}, \mathrm{NO}_{2}$, and $\mathrm{NH}_{3}$ ). Identifying the type and quantifying the relative

409 amounts of each species of $\mathrm{N}$ could provide a clearer link between urbanization and $\mathrm{N}$

410 deposition, as different forms of $\mathrm{N}$ are important for both plant and rhizobia physiology and

411 metabolism (Wallsgrove et al. 1983). In addition to further investigation of soil $\mathrm{N}$ content, soil

$412 \delta^{15} \mathrm{~N}$ could integrate inputs, metabolic processes, and transformations of $\mathrm{N}$ in ecosystems

413 (Robinson 2001). For example, a typical fertilizer has a $\delta^{15} \mathrm{~N}$ around $0 \%$ and other

414 anthropogenic sources have enriched $\delta^{15} \mathrm{~N}$ signatures (Robinson 2001, Michener and Lajtha

415 2007), which can be reflected in the tissues of organisms utilizing these sources (Robinson 2001,

416 Trammell et al. 2016). Urban environments frequently have increased and less variable soil $\delta^{15} \mathrm{~N}$

417 relative to nearby nonurban or rural environments (Trammell et al. 2020). Therefore, using soil

$418 \delta^{15} \mathrm{~N}$ could also help to identify a direct link from urbanization to changes in soil $\mathrm{N}$ and

419 ultimately legume-rhizobia mutualisms.

$420 \quad$ Limitations 
421 Our study had several limitations that contextualize our conclusions. First, we focused on the

422 focal white clover-rhizobia mutualism without considering how other coexisting plants could

423 affect the focal mutualism and soil nutrient patterns. White clover was frequently collected in

424 patches of grass, especially Poa апnиа, and near other legumes, predominantly Medicago

425 lupulina and occasionally other Trifolium species (T. pratense, T. hybridum; DMS, personal

426 observation). White clover competes for space and nutrients with these other plants and this

427 competition could have affected the response of the focal mutualism to urbanization, especially if

428 plant species composition changed along the urbanization gradient as has been reported

429 elsewhere (Hope et al. 2003, Knapp et al. 2008, 2012). Other legumes might have also affected

430 the observed patterns in soil N, although we did explicitly avoid collecting soil from patches of

431 other legume species so this possibility is unlikely. Second, we did not investigate how the

432 microbial community beyond rhizobium in the soil and in the roots of white clover varies with

433 urbanization. Microbes are crucial for plant community assembly and responses to biotic and

434 abiotic stress (van der Heijden et al. 2008, Fitzpatrick et al. 2018). Additionally, the ostensibly

435 pairwise mutualistic interaction between white clover and rhizobia can be altered in the presence

436 of other bacteria or fungi (Heath and Tiffin 2007, García Parisi et al. 2015). With recent studies

437 documenting changes in microbial diversity and composition in response to urbanization (Xu et

438 al. 2014, Reese et al. 2016), it is plausible that variation in microbial communities in the mosaic

439 of urban environments could alter the ecological effects of the white clover-rhizobium

440 interaction and shift the cost-benefit balance of the mutualism (García Parisi et al. 2015,

441 Burghardt et al. 2018, Batstone et al. 2020). Lastly, temporal variation in $\mathrm{N}$ deposition could

442 have a differential effect on soil $\mathrm{N}$ along the urbanization gradient (Zbieranowski and Aherne

443 2011, 2012), with rural soil $\mathrm{N}$ being more variable than urban soil N (Trammell et al. 2020). As 
444 we only measured white clover $\delta^{15} \mathrm{~N}$, we were only able to identify the $\mathrm{N}$ source integrated into

445 plant tissue over the growing season and account for temporal variation in N sources. Measuring

446 soil $\delta^{15} \mathrm{~N}$ would have traced potential changes to $\mathrm{N}$ inputs in the system, but temporal variation in

447 soil $\mathrm{N}$ and linkages to a legume-rhizobia mutualism was outside the scope of this study.

448 Notwithstanding these limitations, our study shows that urbanization alters the ecological and

449 ecosystem-level effects of the white clover-rhizobia mutualism.

\section{$450 \quad$ Conclusion}

451 Our study represents an evaluation of the effects of urbanization on an ecologically-important

452 mutualism. To date, urban ecological research has principally evaluated species interactions by

453 focusing on plant-pollinator and plant-herbivore interactions (Youngsteadt et al. 2015, Aronson

454 et al. 2016, Harrison et al. 2018, Miles et al. 2019, Rivkin et al. 2020). We have extended this

455 field by investigating the mutualistic interaction between a plant (white clover) and its

456 mutualistic, microbial symbionts (rhizobia). White clover invested in more nodules and relied on

457 rhizobia for $\mathrm{N}$ fixation with less urbanization, and increased urbanization directly and negatively

458 affected investment in rhizobia by white clover, with soil $\mathrm{N}$ playing a critical role linking

459 urbanization to the mutualistic interaction between white clover and rhizobia. In conclusion, our

460 results demonstrate the direct and indirect effects of urbanization on the cost-benefit balance and

461 ecological consequences of a legume-rhizobium mutualism. 


\section{Data Accessibility Statement}

463 Data and code are available on Zenodo <http://doi.org/10.5281/zenodo.4459724> (Murray-

464 Stoker and Johnson 2021).

\section{Acknowledgements}

466 We thank S. Munim and K. Murray-Stoker for assistance with field work and C. Sastropranoto

467 for help with soil sample processing. We thank R. Rivkin, J. Santangelo, L. Albano, S. Breitbart,

468 S. Koch, and L. Miles for providing comments on earlier drafts of the manuscript.

$469 \quad$ Funding

470 This work was funded by an NSERC Discovery Grant, Canada Research Chair, and E.W.R.

471 Steacie Fellowship to M. T. J. Johnson.

472 Author Contributions

473 David Murray-Stoker: Conceptualization (Equal); Data curation (Lead); Formal analysis (Lead);

474 Investigation (Equal); Methodology (Equal); Writing-original draft (Lead); Writing-review \&

475 editing (Equal)

476 Marc T. J. Johnson: Conceptualization (Equal); Data curation (Supporting); Formal analysis

477 (Supporting); Funding acquisition (Lead); Investigation (Equal); Methodology (Equal); Writing-

478 original draft (Supporting); Writing-review \& editing (Equal) 


\section{References}

Andrews, M. and Andrews, M. E. 2017. Specificity in legume-rhizobia symbioses. - Int. J. Mol. Sci. 18: 705.

Aronson, M. F. J. et al. 2016. Hierarchical filters determine community assembly of urban species pools. - Ecology 97: 2952-2963.

Baker, M. J. and Williams, W. M. 1987. White Clover. - C.A.B. International.

Barrett, J. P. and Silander, J. A. 1992. Seedling recruitment limitation in white clover (Trifolium repens; Leguminosae). - Am. J. Bot. 79: 643-649.

Barton, K. 2020. MuMIn: Multi-Model Inference. - R package version 1.43.17. <https://CRAN.R-project.org/package=MuMIn>

Bates, D. et al. 2015. Fitting linear mixed-effects models using lme4. - J. Stat. Softw. 67: 1-48.

Batstone, R. T. et al. 2020. Experimental evolution makes microbes more cooperative with their local host genotype. - Science 370: 476-478.

Burghardt, L. T. et al. 2018. Select and resequence reveals relative fitness of bacteria in symbiotic and free-living environments. - Proc. Natl. Acad. Sci. U. S. A. 115: 24252430.

Clearwater, R. L. et al. 2016. Environmental sustainability of Canadian agriculture: Agrienvironmental indicator report series-Report \#4. - Agriculture and Agri-Food Canada.

Cleland, E. E. and Harpole, W. S. 2010. Nitrogen enrichment and plant communities. - Ann. N. Y. Acad. Sci. 1195: 46-61.

Craine, J. M. et al. 2015. Ecological interpretations of nitrogen isotope ratios of terrestrial plants and soils. - Plant Soil 396: 1-26.

De León, L. F. et al. 2019. Urbanization erodes niche segregation in Darwin's finches. - Evol. Appl. 12: 1329-1343.

Fitzpatrick, C. R. et al. 2018. Assembly and ecological function of the root microbiome across angiosperm plant species. - Proc. Natl. Acad. Sci. U. S. A. 115: E1157-E1165.

Forrester, N. J. and Ashman, T.-L. 2018. Nitrogen fertilization differentially enhances nodulation and host growth of two invasive legume species in an urban environment. - J. Urban Ecol. 4: juy021.

Galloway, J. N. et al. 2003. The nitrogen cascade. - BioScience 53: 341.

Gano-Cohen, K. A. et al. 2020. Recurrent mutualism breakdown events in a legume rhizobia metapopulation. - Proc. R. Soc. B Biol. Sci. 287: 20192549.

García Parisi, P. A. et al. 2015. Multi-symbiotic systems: functional implications of the coexistence of grass-endophyte and legume-rhizobia symbioses. - Oikos 124: 553-560.

Grace, J. 2006. Structural Equation Modeling and Natural Systems. - Cambridge University Press.

Grace, J. B. et al. 2010. On the specification of structural equation models for ecological systems. - Ecol. Monogr. 80: 67-87.

Grimm, N. B. et al. 2008. Global change and the ecology of cities. - Science 319: 756-760.

Groffman, P. M. et al. 2014. Ecological homogenization of urban USA. - Front. Ecol. Environ. 12: 74-81.

Harrison, J. G. et al. 2018. Deconstruction of a plant-arthropod community reveals influential plant traits with nonlinear effects on arthropod assemblages. - Funct. Ecol. 32: 13171328.

Hartig, F. 2020. DHARMa: Residual Diagnostics for Hierarchical (Multi-Level / Mixed) Regression Models. - R package version 0.3.3.0. <https://CRAN.R- 
Hastie, T. and Tibshirani, R. 1986. Generalized additive models. - Stat. Sci. 1: 291-310.

Heath, K. D. and Tiffin, P. 2007. Context dependence in the coevolution of plant and rhizobial mutualists. - Proc. R. Soc. B Biol. Sci. 274: 1905-1912.

Heath, K. D. et al. 2010. Mutualism variation in the nodulation response to nitrate. - J. Evol. Biol. 23: 2494-2500.

Hijmans, R. J. 2019. geosphere: Spherical Trigonometry. - R package version 1.5-10. <https://CRAN.R-project.org/package=geosphere>

Hirsch, A. M. 1992. Developmental biology of legume nodulation. - New Phytol. 122: 211-237. Högberg, P. 1997. 15N natural abundance in soil-plant systems. - New Phytol. 137: 179-203.

Hope, D. et al. 2003. Socioeconomics drive urban plant diversity. - Proc. Natl. Acad. Sci. U. S. A. 100: 8788-8792.

Irwin, R. E. et al. 2014. Plant-animal interactions in suburban environments: implications for floral evolution. - Oecologia 174: 803-815.

Johnson, M. T. J. et al. 2018. Contrasting the effects of natural selection, genetic drift and gene flow on urban evolution in white clover (Trifolium repens). - Proc. R. Soc. B Biol. Sci. 285: 20181019.

Kaye, J. et al. 2006. A distinct urban biogeochemistry? - Trends Ecol. Evol. 21: 192-199.

Kemball, W. D. and Marshall, C. 1995. Clonal integration between parent and branch stolons in white clover: a developmental study. - New Phytol. 129: 513-521.

Knapp, S. et al. 2008. Challenging urban species diversity: contrasting phylogenetic patterns across plant functional groups in Germany. - Ecol. Lett. 11: 1054-1064.

Knapp, S. et al. 2012. Phylogenetic and functional characteristics of household yard floras and their changes along an urbanization gradient. - Ecology 93: S83-S98.

Kuznetsova, A. et al. 2017. lmerTest package: tests in linear mixed effects models. - J. Stat. Softw. 82: 1-26.

Lau, J. A. et al. 2012. Direct and interactive effects of light and nutrients on the legume-rhizobia mutualism. - Acta Oecologica 39: 80-86.

Leibold, M. A. and Chase, J. M. 2017. Metacommunity Ecology. - Princeton University Press.

Martínez-Romero, E. and Caballero-Mellado, J. 1996. Rhizobium phylogenies and bacterial genetic diversity. - Crit. Rev. Plant Sci. 15: 113-140.

McKinney, M. L. 2002. Urbanization, biodiversity, and conservation. - BioScience 52: 883-890.

Michener, R. and Lajtha, K. 2007. Stable Isotopes in Ecology and Environmental Science. Blackwell Publishing.

Miles, L. S. et al. 2019. Urbanization shapes the ecology and evolution of plant-arthropod herbivore interactions. - Front. Ecol. Evol. 7: 310.

Mitchell, R. J. 1992. Testing evolutionary and ecological hypotheses using path analysis and structural equation modelling. - Funct. Ecol. 6: 123-129.

Murray-Stoker, D., and M Johnson. 2021. Data from: dmurraystoker/TRhizo-urbanTerreN: Ecological consequences of urbanization on a legume-rhizobia mutualism (Version V1.0). - Zenodo <http://doi.org/10.5281/zenodo.4459724>

Nakagawa, S. et al. 2017. The coefficient of determination $\mathrm{R}^{2}$ and intra-class correlation coefficient from generalized linear mixed-effects models revisited and expanded. - J. R. Soc. Interface 14: 20170213.

Omrane, S. and Chiurazzi, M. 2009. A variety of regulatory mechanisms are involved in the nitrogen-dependent modulation of the nodule organogenesis program in legume roots. - 
Plant Signal. Behav. 4: 1066-1068.

Parsons, A. W. et al. 2019. Urbanization focuses carnivore activity in remaining natural habitats, increasing species interactions. - J. Appl. Ecol. 56: 1894-1904.

Poole, P. et al. 2018. Rhizobia: from saprophytes to endosymbionts. - Nat. Rev. Microbiol. 16: 291-303.

Porter, S. S. and Simms, E. L. 2014. Selection for cheating across disparate environments in the legume-rhizobium mutualism. - Ecol. Lett. 17: 1121-1129.

Pouyat, R. V. et al. 2015. A global comparison of surface soil characteristics across five cities: a test of the urban ecosystem convergence hypothesis. - Soil Sci. 180: 136-145.

R Core Team 2020. R: a language and environment for statistical computing. - version 4.0.3. $<$ https://cran.r-project.org/>

R Studio Team 2020. RStudio: Integrated development for R. - version 1.4.869. <https://www.rstudio.com/>

Raupp, M. J. et al. 2010. Ecology of herbivorous arthropods in urban landscapes. - Annu. Rev. Entomol. 55: 19-38.

Reese, A. T. et al. 2016. Urban stress is associated with variation in microbial species composition-but not richness-in Manhattan. - ISME J. 10: 751-760.

Regus, J. U. et al. 2017. Nitrogen deposition decreases the benefits of symbiosis in a native legume. - Plant Soil 414: 159-170.

Rivkin, L. R. et al. 2020. Variation in pollinator-mediated plant reproduction across an urbanization gradient. - Oecologia 192: 1073-1083.

Robinson, D. 2001. $\delta^{15} \mathrm{~N}$ as an integrator of the nitrogen cycle. - Trends Ecol. Evol. 16: 153-162.

Rocha, E. A. and Fellowes, M. D. E. 2018. Does urbanization explain differences in interactions between an insect herbivore and its natural enemies and mutualists? - Urban Ecosyst. 21: 405-417.

Rosseel, Y. 2012. lavaan: an R package for structural equation modeling. - J. Stat. Softw. 48: 136.

Santangelo, J. S. et al. 2020. Multivariate phenotypic divergence along an urbanization gradient. - Biol. Lett. 16: 20200511.

Satorra, A. and Bentler, P. M. 2001. A scaled difference chi-square test statistic for moment structure analysis. - Psychometrika 66: 507-514.

Satterthwaite, F. E. 1946. An approximate distribution of estimates of variance components. Biom. Bull. 2: 110-114.

Seto, K. C. et al. 2010. The new geography of contemporary urbanization and the environment. Annu. Rev. Environ. Resour. 35: 167-194.

Simonsen, A. K. et al. 2015. Short-term fertilizer application alters phenotypic traits of symbiotic nitrogen fixing bacteria. - PeerJ 3: e1291.

Stevens, C. J. et al. 2018. Atmospheric nitrogen deposition in terrestrial ecosystems: Its impact on plant communities and consequences across trophic levels. - Funct. Ecol. 32: 17571769.

Streeter, J. G. 1985. Nitrate inhibition of legume nodule growth and activity. - Plant Physiol. 77: 325-328.

Streeter, J. and Wong, P. P. 1988. Inhibition of legume nodule formation and $\mathrm{N}_{2}$ fixation by nitrate. - Crit. Rev. Plant Sci. 7: 1-23.

Thompson, K. A. et al. 2016. Urbanization drives the evolution of parallel clines in plant populations. - Proc. R. Soc. B Biol. Sci. 283: 20162180. 
Thomson, D. M. and Page, M. L. 2020. The importance of competition between insect pollinators in the Anthropocene. - Curr. Opin. Insect Sci. 38: 55-62.

Trammell, T. L. E. et al. 2016. Plant nitrogen concentration and isotopic composition in residential lawns across seven US cities. - Oecologia 181: 271-285.

Trammell, T. L. E. et al. 2020. Urban soil carbon and nitrogen converge at a continental scale. Ecol. Monogr. 90: e01401.

Tuck, S. L. et al. 2014. MODISTools - downloading and processing MODIS remotely sensed data in R. - Ecol. Evol. 4: 4658-4668.

van der Heijden, M. G. A. et al. 2008. The unseen majority: soil microbes as drivers of plant diversity and productivity in terrestrial ecosystems. - Ecol. Lett. 11: 296-310.

Vergeer, P. et al. 2008. Geographical variation in the response to nitrogen deposition in Arabidopsis lyrata petraea. - New Phytol. 179: 129-141.

Wallsgrove, R. M. et al. 1983. Photosynthesis, photorespiration and nitrogen metabolism. - Plant Cell Environ. 6: 301-309.

Weese, D. J. et al. 2015. Long-term nitrogen addition causes the evolution of less-cooperative mutualists. - Evolution 69: 631-642.

Wickham, H. et al. 2019. Welcome to the tidyverse. - J. Open Source Softw. 4: 1686.

Williams, N. S. G. et al. 2009. A conceptual framework for predicting the effects of urban environments on floras. - J. Ecol. 97: 4-9.

Wisz, M. S. et al. 2013. The role of biotic interactions in shaping distributions and realised assemblages of species: implications for species distribution modelling. - Biol. Rev. 88: $15-30$.

Wood, S. N. 2003. Thin plate regression splines. - J. R. Stat. Soc. Ser. B Stat. Methodol. 65: 95114.

Wood, S. N. 2011. Fast stable restricted maximum likelihood and marginal likelihood estimation of semiparametric generalized linear models. - J. R. Stat. Soc. Ser. B Stat. Methodol. 73: 3-36.

Wood, S. N. 2017. Generalized Additive Models: An Introduction with R, Second Edition. Chapman and Hall/CRC.

Wright, S. 1934. The method of path coefficients. - Ann. Math. Stat. 5: 161-215.

$\mathrm{Xu}, \mathrm{H} .-\mathrm{J}$. et al. 2014. Does urbanization shape bacterial community composition in urban park soils? A case study in 16 representative Chinese cities based on the pyrosequencing method. - FEMS Microbiol. Ecol. 87: 182-192.

Youngsteadt, E. et al. 2015. Do cities simulate climate change? A comparison of herbivore response to urban and global warming. - Glob. Change Biol. 21: 97-105.

Zbieranowski, A. L. and Aherne, J. 2011. Long-term trends in atmospheric reactive nitrogen across Canada: 1988-2007. - Atmos. Environ. 45: 5853-5862.

Zbieranowski, A. L. and Aherne, J. 2012. Ambient concentrations of atmospheric ammonia, nitrogen dioxide and nitric acid across a rural-urban-agricultural transect in southern Ontario, Canada. - Atmos. Environ. 62: 481-491.

Zhang, L. et al. 2012. Nitrogen deposition to the United States: distribution, sources, and processes. - Atmospheric Chem. Phys. 12: 4539-4554.

Zheng, M. et al. 2019. Global pattern and controls of biological nitrogen fixation under nutrient enrichment: A meta $\square$ analysis. - Glob. Change Biol. 25: 3018-3030.

Ziter, C. 2016. The biodiversity-ecosystem service relationship in urban areas: a quantitative review. - Oikos 125: 761-768. 


\section{Figures (with captions)}

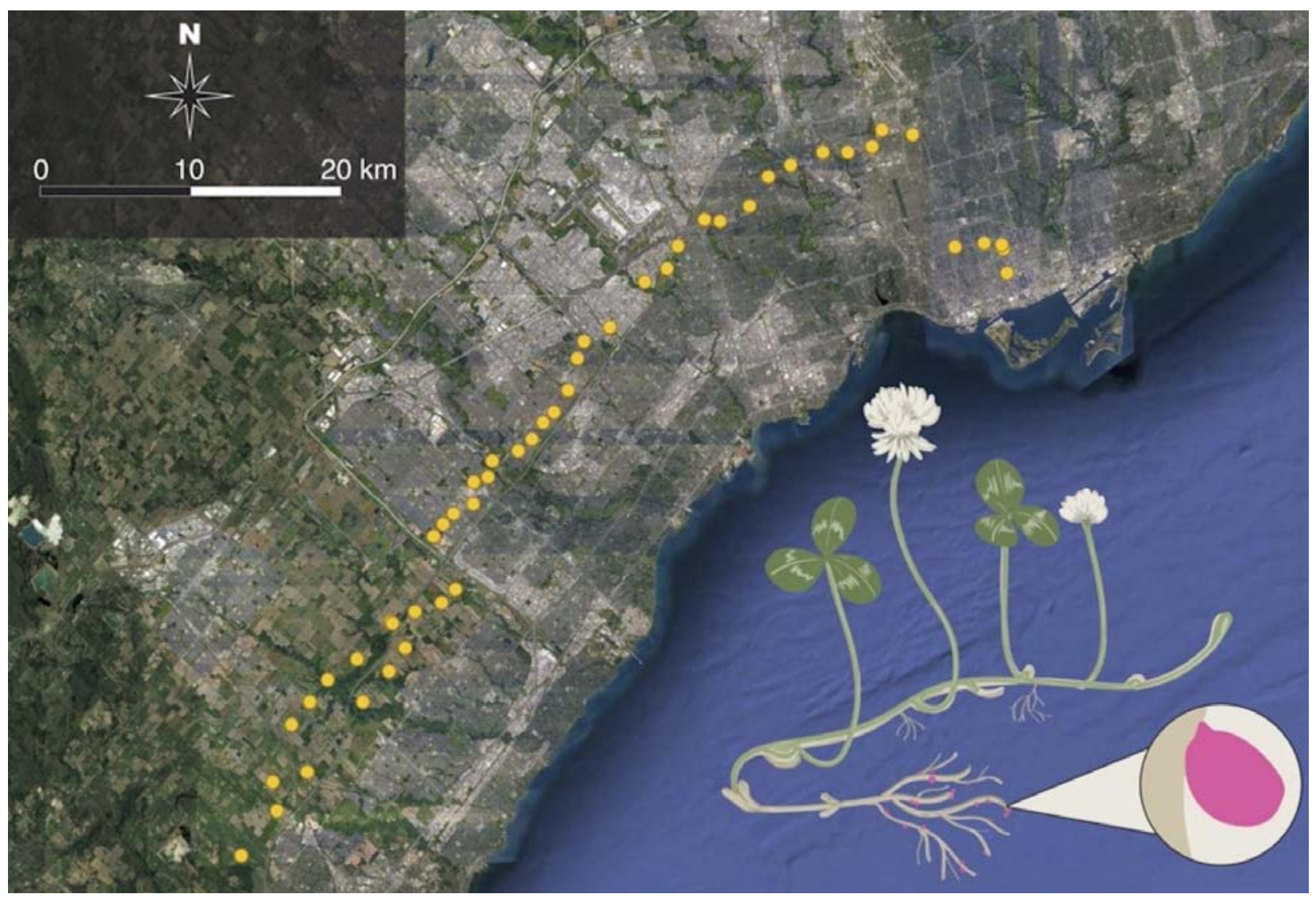

665 Figure 1. Map of the urbanization gradient in the Greater Toronto Area, ON, Canada displaying

666 all 49 sampling sites for the study. The inset displays an illustration of a typical white clover

667 individual sampled in the field, and the callout depicts a nodule attached to the root. Satellite

668 imagery was taken in 2018 and retrieved from Google. 


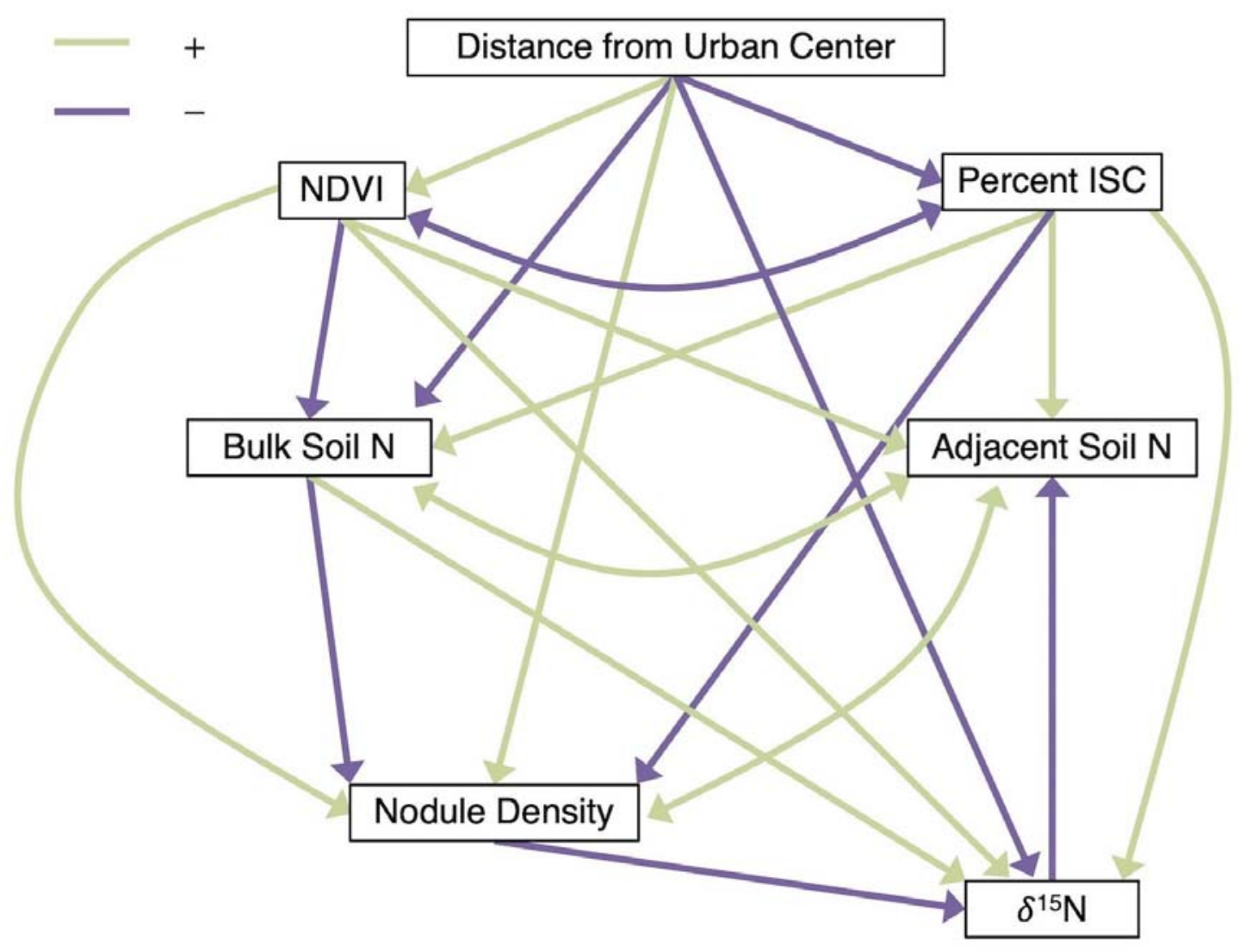

670 Figure 2. Hypothesized path model specifying causal and correlational pathways and the

671 associated direction of each relationship. The structural set of linear equations for each causal or

672 correlational pathway can be described by variables linking the response to the predictor (e.g.,

673 bulk soil $\mathrm{N} \sim$ percent ISC + NDVI + distance). Distance from the urban center was fitted to

674 account for extraneous sources of urbanization and environmental variation not explained by

675 other predictors. We hypothesized that changes to local environments in the urban landscape

676 would manifest in direct effects of urbanization (i.e., percent ISC and NDVI) on both soil N and

677 the legume-rhizobia mutualism (i.e., nodule density and white clover $\delta^{15} \mathrm{~N}$ ), with indirect effects

678 of urbanization mediated through soil $\mathrm{N}$. 

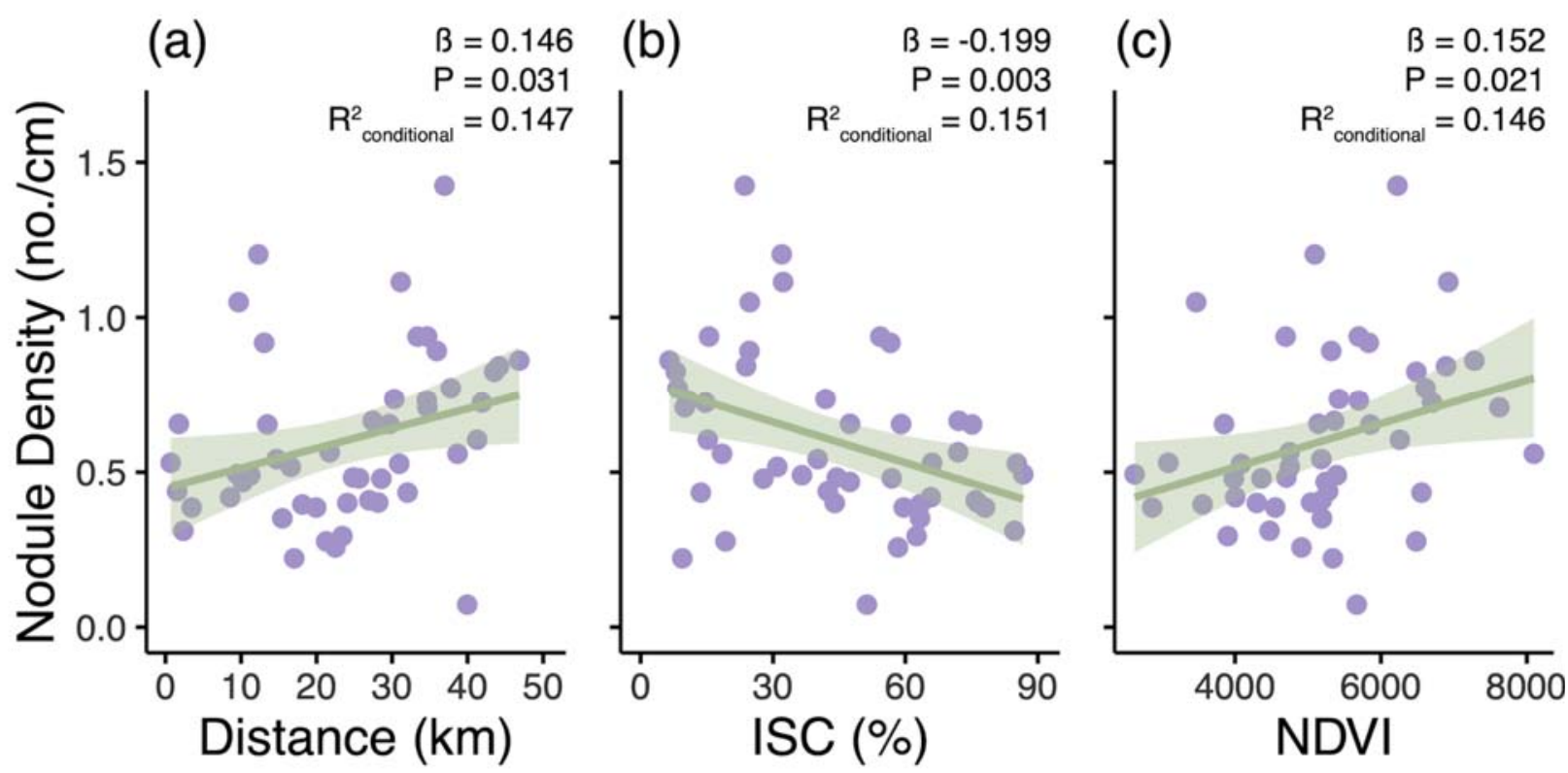

680 Figure 3. Plots of nodule density against (a) distance from the urban center (Distance), (b)

681 percent impervious surface cover (ISC), and (c) normalized difference vegetation index (NDVI).

682 Lines are lines-of-best-fit ( \pm standard error) from a linear mixed effects model, with the

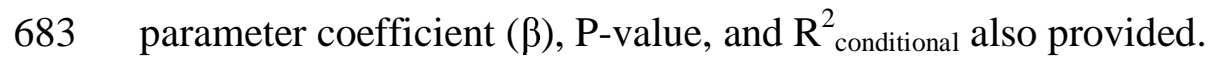



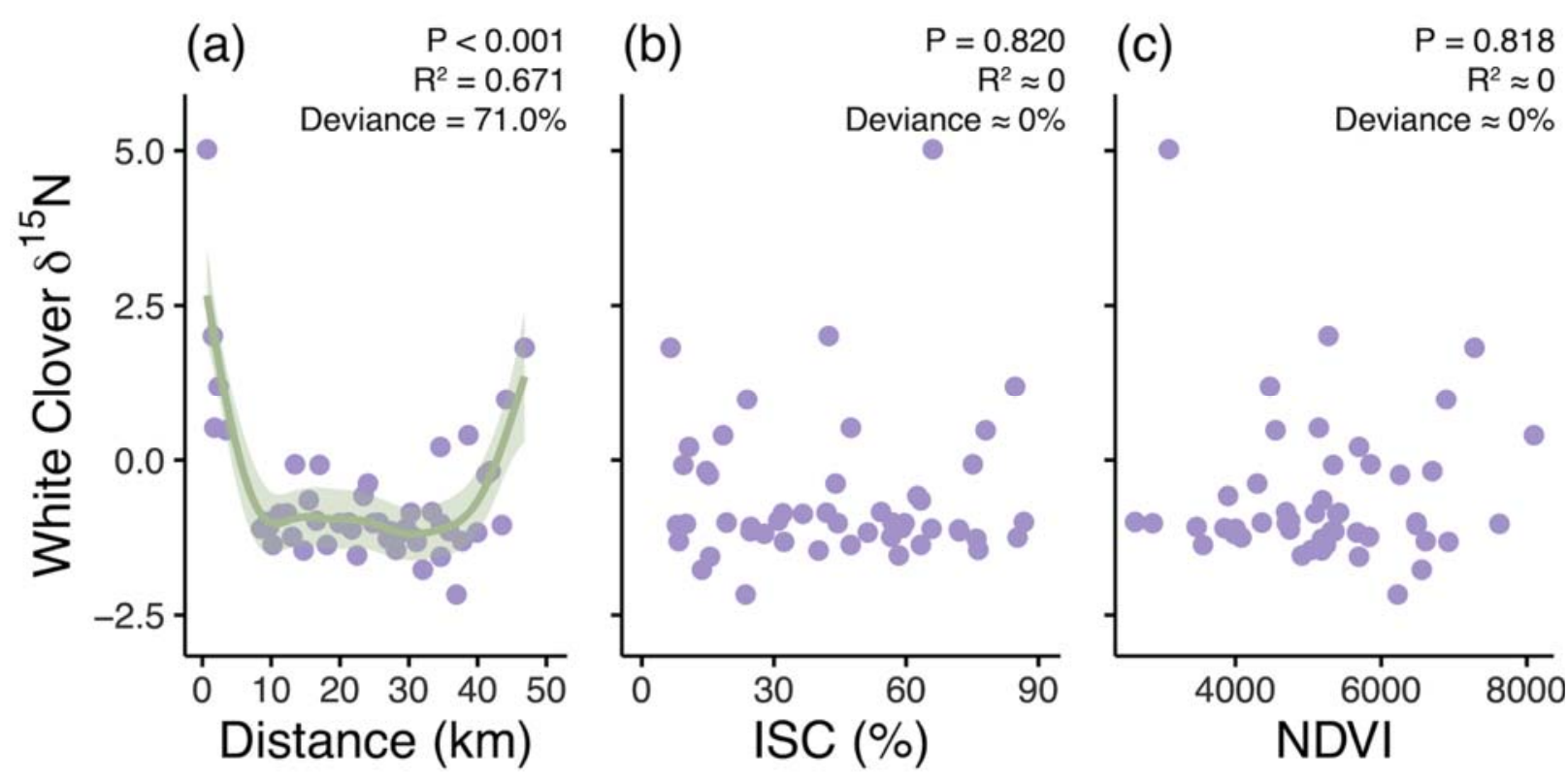

685 Figure 4. Plots of white clover $\delta^{15} \mathrm{~N}$ against (a) distance from the urban center (Distance), (b)

686 percent impervious surface cover (ISC), and (c) normalized difference vegetation index (NDVI).

687 Lines are smoothed curves ( \pm standard error) from a generalized additive model, with the P-

688 value, $\mathrm{R}^{2}$, and deviance explained (deviance) also provided. Percent ISC and NDVI were not

689 ecologically-relevant predictors of white clover $\delta^{15} \mathrm{~N}$ so lines are not displayed. 


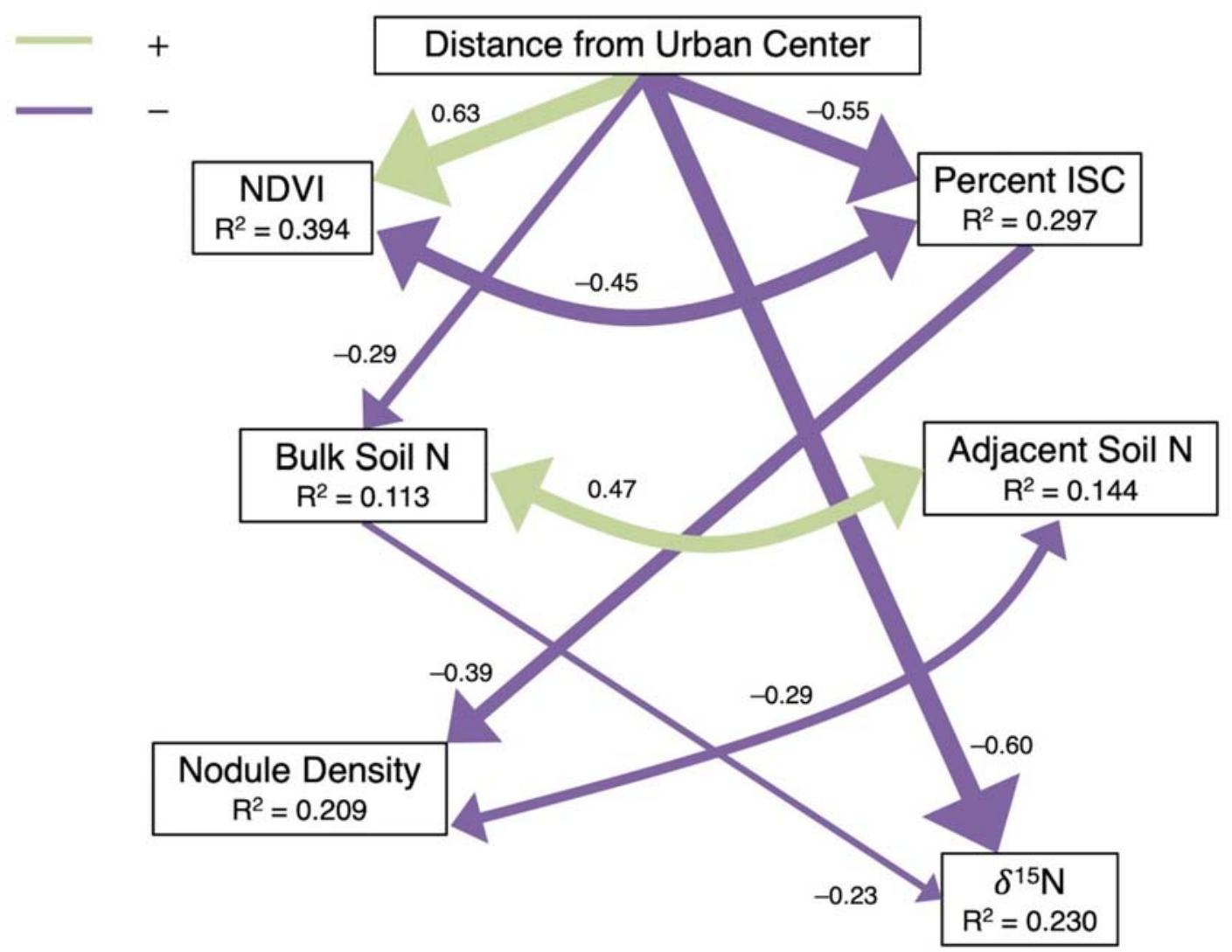

691 Figure 5. Path diagram showing the causal interactions between distance from the urban center,

692 percent impervious surface cover (ISC), normalized difference vegetation index (NDVI), soil N

693 (bulk and adjacent), nodule density, and white clover $\delta^{15} \mathrm{~N}$. The model had good fit between the

694 predicted and observed covariance $\left(\chi^{2}=0.009\right.$, $\left.\mathrm{df}=1, \mathrm{P}=0.926\right)$. Lines represent influential

695 causal pathways in the model $(\mathrm{P}<0.10)$, with single-headed arrows indicating an unidirectional

696 pathway and double-headed arrows indicating a correlation between variables. Purple lines

697 represent negative pathways, while green lines represent positive pathways; non-influential

698 pathways are not displayed. Standardized path coefficients, which show the direction and

699 magnitude of the relationship between variables, are reported next to each line and line widths

700 are scaled relative to the magnitude of the path coefficients. The $\mathrm{R}^{2}$ is reported for each

701 endogenous variable. 


\section{Tables (with captions)}

703 Table 1. Summary of the nodule density linear mixed-effects model comparing nodule density

704 against distance from the urban center (distance), percent impervious surface cover (ISC), and

705 normalized difference vegetation index (NDVI). We report coefficients ( $\beta$, slope parameter),

706 standard errors of the coefficients (SE), numerator degrees-of-freedom (NDF), denominator

707 degrees-of-freedom (DDF) approximated following the Satterthwaite method, partial $F$-statistics

708 calculated from Type II sums-of-squares, P-values, and $\mathrm{R}_{\text {conditional. }}^{2}$

\begin{tabular}{lrrrrrrr}
\hline \multicolumn{1}{c}{ Term } & \multicolumn{1}{c}{$\boldsymbol{\beta}$} & SE & NDF & DDF & \multicolumn{1}{c}{$\boldsymbol{F}$} & P-value & $\mathbf{R}_{\text {condidtional }}$ \\
\hline Distance & 0.146 & 0.066 & 1 & 47.723 & 4.949 & 0.031 & 0.147 \\
Percent ISC & -0.199 & 0.063 & 1 & 51.839 & 10.042 & 0.003 & 0.151 \\
NDVI & 0.152 & 0.064 & 1 & 55.268 & 5.640 & 0.021 & 0.146 \\
\hline
\end{tabular}

709 
710 Table 2. Summary of the white clover $\delta^{15} \mathrm{~N}$ generalized additive models (GAMs) comparing

711 white clover $\delta^{15} \mathrm{~N}$ against distance from the urban center (distance), percent impervious surface

712 cover (ISC), and NDVI. We report estimated degrees-of-freedom (EDF), which can differ from 1

713 because the values are penalized for smoothed parameters; an EDF = 1 would suggest a linear

714 relationship. Reference degrees-of-freedom (REF.df) are used for calculating $F$-statistics and P-

715 values for each smoothed term. We also report the $\mathrm{R}^{2}$ and deviance explained for each model, as

716 well as the $\chi^{2}$ statistic associated with the smooth term.

\begin{tabular}{lrrrrrr}
\hline \multicolumn{1}{c}{ Term } & EDF & REF.df & $\boldsymbol{F}$ & P-value & $\mathbf{R}^{2}$ & Deviance Explained \\
\hline Distance & 5.654 & 9 & 10.893 & $<0.001$ & 0.671 & $71 \%$ \\
Percent ISC & $<0.001$ & 9 & $<0.001$ & 0.820 & $\cong 0.000$ & $\cong 0 \%$ \\
NDVI & $<0.001$ & 9 & $<0.001$ & 0.818 & $\cong 0.000$ & $\cong 0 \%$ \\
\hline
\end{tabular}

717 Note: As the white clover $\delta^{15} \mathrm{~N}$ GAMs were fitted to a Gaussian error distribution, $F$-statistics

718 were calculated instead of $\chi^{2}$-statistics. 